\title{
Interactions between physical and psychosocial risk factors at work increase the risk of back disorders: an epidemiological approach
}

\author{
J Jason Devereux, Peter W Buckle, Ioannis G Vlachonikolis
}

\begin{abstract}
Objectives-To investigate the possible interactions between physical and psychosocial risk factors at work that may be associated with self reported back disorders.

Methods-891 of 1514 manual workers, delivery drivers, technicians, customer services computer operators, and general office staff reported risk factors at work and back disorders with a self administered questionnaire ( $59 \%$ return rate). Of the 869 respondents with a valid questionnaire, 638 workers were classified in to one of four exposure groups: high physical and high psychosocial; high physical and low psychosocial; low physical and high psychosocial; and low physical and low psychosocial. Low physical and low psychosocial was used as an internal reference group. The exposure criteria were derived from existing epidemiological publications and models for physical and psychosocial work factors. The frequency and amplitude of lifting and the duration spent sitting while experiencing vibration were used as physical exposure criteria. Ordinal values of mental demands, job control, and social support from managers and coworkers were used as psychosocial exposure criteria.

Results-The highest increase in risk was found in the high physical and high psychosocial exposure group for symptoms of back disorders. In the crude and multivariate analyses, a departure from an additive risk model was found for the 7 day prevalence of symptoms of a low back disorder and also for a recurrent back disorder not present before the current job but also experienced in the past 7 days. Conclusion-This study suggests that an interaction between physical and psychosocial risk factors at work may exist to increase the risk of self reported back disorders. Ergonomic prevention strategies that aim to minimise the risks of symptoms of work related back disorders should not only focus on physical but also on psychosocial risk factors at work. The greatest benefits are likely to be realised when both physical and psychosocial factors are put right.

(Occup Environ Med 1999;56:343-353)
\end{abstract}

Keywords: low back pain; epidemiology, manual work, psychosocial work factors
Recent literature reviews have shown that workplace factors may be determinants of back disorders. ${ }^{1-7}$ A common framework in these reviews dichotomises workplace factors into physical and psychosocial factors. Physical risk factors at work have included heavy manual work, frequent lifting or carrying, whole body vibration, frequent bending and twisting, and static work postures. Psychosocial risk factors at work have included perceived high pressure on time and workload, low job control, job dissatisfaction, monotonous work, and low support from coworkers and management.

The relative importance of physical and psychosocial risk factors at work in the aetiology of back disorders has not yet been established. Some of the more recent epidemiological studies have simultaneously investigated physical and psychosocial work factors and back disorders. ${ }^{8-15}$ The methods of these studies have primarily aimed at identifying the independent effects of each set of factors upon back problems. However, physical and psychosocial work factors coexist and may potentially interact to increase the risk. These possible effects of interaction between physical and psychosocial risk factors at work and work related musculoskeletal disorders have not been satisfactorily investigated. ${ }^{2}$ The aim of this study was, therefore, to investigate the potential interaction between these work related risk factors and self reported back disorders.

In publications on epidemiology, interactions have been defined as a departure from a multiplicative or an additive risk model when exposed to both determinants of disease. ${ }^{16}$ The decision about which model to use should ideally be based upon the biological mechanism under investigation. ${ }^{16-18}$ However, the biological mechanisms of back disorders and other work related musculoskeletal disorders are not sufficiently understood to enable such a choice to be made, ${ }^{19}$ although this does not imply that the choice can be selected arbitrarily. Koopman ${ }^{18}$ showed that additive and multiplicative models may be inconsistent with each other when modelling interactions between determinants of disease - for example, no interaction in a multiplicative model may imply a positive interaction with an additive model. The choice of epidemiological risk model should, therefore, not be arbitrary. Deviations from an additive model should be assessed for measuring interaction between determinants for public health concerns even when such data agree with a multiplicative model without interaction. ${ }^{16-18}$ 
We designed an epidemiological study, with an additive risk model, to study whether an interaction was present between physical and psychosocial factors at work that increased the risk of back disorders. The potential existence of such interactions could be important in reducing ergonomic risks in the workplace.

\section{Material and methods}

The study population comprised 1514 male and female workers from 26 randomly selected sites of a United Kingdom company. Manual workers, delivery drivers, customer services queries workers, computer workers, and general office staff completed a self administered questionnaire covering personal data and demographics, physical and psychosocial work factors, and musculoskeletal symptoms. The questions on physical work factors refer to current day exposures, which have been validated in a study comparing self reported responses with instrument recordings. ${ }^{20}$ Most of the physical factor questions had a $\kappa$ coefficient $\geqslant 0.4$ (except for stooped back posture and trunk rotation). The questions on psychosocial work factors have been validated in a study on the internal consistency of all the psychosocial factors. ${ }^{21}$ Acceptable internal consistency $\alpha$ coefficients between $0.65-0.95$ were reported.

Data on job title, age, and sex were obtained for each worker in the study population from personnel records to compare survey respondents and non-respondents. The prevalence of back disorders was obtained from company medical severance data over a 5 year period to investigate any potential healthy worker effects. Permission for the cross sectional epidemiological study was obtained from the University of Surrey committee on ethics.

\section{EXPOSURE CLASSIFICATION}

Each worker responding to the cross sectional survey was classified for physical and psychosocial exposure. The four exposure groups were: low physical exposure-low psychosocial exposure; low physical exposure-high psychosocial exposure; high physical exposure-low psychosocial exposure; high physical exposure-high psychosocial exposure.

Each worker that satisfied the criteria of one of four exposure groups was classified in that group. A worker could not be classified into more than one exposure group. Workers in the low physical-low psychosocial exposure group served as an internal reference population for the other three exposure groups.

Each of the survey respondents was classified into one of two psychosocial exposure strata, high or low, and three physical exposure strata, low, high, and undefined. Workers that did not satisfy the criteria for classification into the low or high physical exposure group were classified into the undefined group. The undefined group represents workers who may have relatively high levels of physical exposure compared with the low physical exposure group but do not satisfy the criteria for high physical exposure classification. Also the undefined group would be subject to the greatest degree of self reported bias and could not be classified into a low or high physical exposure group with confidence as the true exposure classification was unclear. This is because self reported questionnaires used for collecting physical exposure data have been shown to have poor validity and reliability but are able to differentiate between low and high exposure groups. ${ }^{2}$ So to minimise self reported bias that may result in exposure misclassification and underestimation of risk, ${ }^{22}$ workers with only low and high physical exposures were used for comparison.

Workers classified into the undefined group were excluded from the analysis of risk. To compare covariates between workers in the undefined and the exposure classified groups the age, sex, years of exposure, and outcome characteristics of those workers included in the risk analysis were compared with the total survey response population.

The exposure criteria were predetermined from a contemporary musculoskeletal disorder model $^{23}$ and also from epidemiological studies that provided a measure of risk for physical and psychosocial work factors associated with back disorders (up to 1995). ${ }^{2}$

\section{Derivation of the physical exposure criteria}

Lifting $>18 \mathrm{~kg}$ has been associated with an increased risk $(>2)$ of low back disorders. ${ }^{24} 25$ This was used as the basis for the first criterion for high physical exposure. Lifting a lower weight $(4.5-11.3 \mathrm{~kg}$ ) very often (once a minute to 25 times a day) has also been associated with an increased risk. ${ }^{26}{ }^{27}$ This was used as the basis for the first term in the second exposure criterion.

It has been continuously asserted that the evidence for associations between low back disorders and sedentary work has been contradictory. ${ }^{628}$ However, sitting combined with vibration has consistently been reported in many studies to increase the risk of back disorders. ${ }^{28-33}$ Driving motor vehicles for $\geqslant 4$ hours a day increased the risk of low back disorders by a factor $>2 .{ }^{34}{ }^{35}$ This formed the basis for the second term in the second exposure criterion for high physical exposure. Armstrong et $a l^{23}$ suggested that it is reasonable that exposure to two known risk factors may additively or multiplicatively increase the risk. Therefore, it is reasonable to suggest that a worker performing light lifting often, and also being exposed to whole body vibration while sitting for a large portion of the day may have an increased risk of experiencing a back disorder. Heavy lifting alone performed often may provide an exposure sufficient to increase the risk of low back disorders without any other exposure present. This rationale was used to formulate the following Boolean algebra expression for high physical exposure criteria from the questionnaire markers (appendix).

High physical exposure criteria:

Lifting $>16 \mathrm{~kg} \geqslant 1-10$ times an hour (criterion 1)

or

Lifting 6-15 $\mathrm{kg} 1-10$ times an hour and experiencing vibration while sitting $\geqslant$ half the working day (criterion 2). 
Table 1 Items and scales used for mental demands, job control, and social support

Mental demands (5 questions):

$1=$ Strongly agree, $2=$ Slightly agree, $3=$ Slightly disagree, $4=$ Strongly disagree

a $\mathrm{My}$ job requires a great deal of concentration

b My job requires me to remember many different things

c I must keep my mind on my work at all times

d I can take it easy and still get my work done

e I can let my mind wander and still do the work

Job control (6 questions):

$1=$ Very little, $2=$ Little, $3=$ A moderate amount, $4=$ Much, 5=Very much

a How much influence do you have over the variety of tasks you perform?

b How much influence do you have over the order in which you perform tasks at work?

c How much influence do you have over the pace of your work, that is how fast or slow do you work?

d How much influence do you have over the decisions concerning which individuals in your work unit do which tasks?

e How much influence do you have over the decisions as to when things will be done in your work unit?

$\mathrm{f}$ How much do you influence the policies, procedures and performance in your work unit? Social support (6 questions):

$1=$ Very much, $2=$ Somewhat, $3=$ A little, $4=$ Not at all, $5=$ Don't have any such person

a How much do each of these people go out of their way to do things to make your work life easier fo you? Your immediate supervisor.

b How much do each of these people go out of their way to do things to make your work life easier fo you? Other people at work.

c How easy is it to talk with each of the following people? Your immediate supervisor.

d How easy is it to talk with each of the following people? Other people at work

e How much can each of these people be relied on when things get tough at work? Your immediate supervisor.

f How much can each of these people be relied on when things get tough at work? Other people at work. mands may produce the lowest psychosocial job strain. Considering the available epidemiological evidence and the model, high psychosocial exposure was defined as follows:

High psychosocial exposure criteria:

- High mental demands

- Low job control

- Low social support.

At least two of the statements for high psychosocial exposure had to be satisfied.

Low psychosocial exposure criteria:

- Low mental demands

- High job control

- High social support.

At least two of the statements for low psychosocial exposure had to be satisfied.

Ordinal scales were used to measure the selected psychosocial work factors. Exposure for each factor was set with selected markers on the scale for each item forming the factor. The selection of markers was based upon the interpretation of the ordinal markers and only partially on the response distributions. Five items formed the mental demand factor, six items formed the job control factor, and six items formed the social support factor as shown in table 1 . To be classified as highly exposed to a psychosocial factor, the response to each item forming the factor had to correspond to the selected markers for that particular ordinal scale. Otherwise a low exposure classification was given.

To be exposed to high mental demands, items $\mathrm{a}-\mathrm{c}$ had to be answered on the scale as 1 - strongly agree - and items $\mathrm{d}$ and e had to be answered on the mental demands scale as 4 - strongly disagree. If item d was answered as 1,2 , or 3 then it was ignored. This was because the item may have been misinterpreted as meaning physical work done or that the response was a halo effect. Halo effects are due to respondents running down the factor items always ticking the same marker because a decision has been made about the perception of the overall factor. ${ }^{43}$ For the same reason, if items $\mathrm{d}$ and e were answered on the scale as 1,2 , or 3 then the individual was excluded from being classified for this psychosocial factor because responses were contradictory unless item $a, b$, and $\mathrm{c}$ were not answered as 1 . In this instance, the criteria for low mental demands had already been satisfied and the answers for items $d$ and $e$ were irrelevant. People who were not classified as being exposed to high mental demands were classified as being exposed to low mental demands.

To be exposed to low job control, items a-f had to be answered on the job control scale as support, ${ }^{14} 38{ }^{39}$ and low job control ${ }^{36}$ were associated with an increased risk of musculoskeletal disorders in general. Psychosocial factors that had been shown to increase the risk of musculoskeletal disorders by a factor of two or more were used as exposure criteria. In accordance with the control model for social support, job demands, and control model, ${ }^{40}$ a combination of low social support, low job control, and high psychological demands may produce the greatest psychosocial job strain and also may result in the highest prevalence of low back problems. ${ }^{41}{ }^{42}$ High social support, high job control, and low psychological de-
Table 2 The number of subjects classified into each exposure group and the number of subjects unclassified

\begin{tabular}{llll}
\hline & \multicolumn{2}{c}{ Psychosocial exposure } & \\
\cline { 2 - 3 } Physical exposure & Low & High & Totals \\
\hline High & 183 & 185 & 368 \\
Low & 147 & 123 & 270 \\
Subtotal & 330 & 308 & 638 \\
Unclassified & 71 & 109 & 180 \\
Total & 401 & 417 & 818 \\
\hline
\end{tabular}


Table 3 Site combined age and cumulative exposure for each sex across exposure groups

\begin{tabular}{|c|c|c|c|c|}
\hline & \multicolumn{4}{|l|}{ Exposure } \\
\hline & $\begin{array}{l}\text { Low physical, low } \\
\text { psychosocial }\end{array}$ & $\begin{array}{l}\text { Low physical, high } \\
\text { psychosocial }\end{array}$ & $\begin{array}{l}\text { High physical, low } \\
\text { psychosocial }\end{array}$ & $\begin{array}{l}\text { High physical, high } \\
\text { psychosocial }\end{array}$ \\
\hline \multicolumn{5}{|l|}{$\operatorname{Sex}(n)$ : } \\
\hline Men & 64 & 53 & 180 & 177 \\
\hline Women & 58 & 63 & 0 & 0 \\
\hline \multicolumn{5}{|c|}{ Age (y, median (interquartile range)): } \\
\hline Men & $46-50(36-55)$ & $36-40(26-45)$ & $(31-45)$ & $(31-50)$ \\
\hline Women & $31-35(26-45)$ & $36-40(26-50)$ & - & - \\
\hline \multicolumn{5}{|c|}{ Duration of the job (y, mean (SD)): } \\
\hline Men & $9.9(10.2)$ & $5.8(8.3)$ & $6.4(7.5)$ & $7.1(8.1)$ \\
\hline Women & $7.1(9.1)$ & $6.9(9.3)$ & - & - \\
\hline
\end{tabular}

Table 4 Prevalence of self reported back pain $/ 100$ workers

\begin{tabular}{ll}
\hline & Prevalence \\
\hline Recurrent back problems lasting $>1$ week or & \\
occurring $>3$ times in the past year & 39 \\
$\begin{array}{l}\text { Prevalence of low back pain in the past } 7 \text { days } \\
\text { Prevalence of low back pain in the past } 12 \text { months }\end{array}$ & 49 \\
$\begin{array}{l}\text { Recurrent back problems not experienced before the } \\
\text { present job and also experienced in the past } 7\end{array}$ & \\
days & 23 \\
\hline
\end{tabular}

1,2 , or 3. People not meeting the criteria were classified as being exposed to high job control.

A person had to have experienced low support from either the supervisor or coworkers to be considered exposed to low social support. To be exposed to low supervisor support, items a, c, and e had to be answered on the support scale as $2,3,4$, or 5 . People not meeting this criterion were classified as exposed to high supervisor support. To be exposed to low coworker support items b, d, and $\mathrm{f}$ had to be answered on the support scale as $2,3,4$, or 5 also. People not meeting this criterion were classified as exposed to high coworker support.

DEFINITION OF OUTCOMES

Back disorders were defined by the prevalence of aches, pain, and discomfort of the lower back within the past 7 days and also the past 12 months. A study has validated these outcome measures against a physical examination with a symptom classification scheme proposed by Nachemson and Andersson in $1982 .^{44}$

Recurrent back disorders were defined as: having experienced problems $>3$ times or for $>1$ week in the previous year, ${ }^{27}{ }^{31}$ not experienced before starting the present job, which were also present within the past 7 days at the time of the survey.

STATISTICAL ANALYSES

The crude odds ratios (ORs) and prevalence rate ratios were estimated for each exposure group with Epi Info 6.

Unconditional multiple logistic regression techniques (SPSS) were used to estimate the ORs for self reported back disorders and each exposure group after controlling for age, sex, and cumulative exposure (years spent in the present job). The maximum likelihood estimates of model variables for the prevalence proportion ratios were obtained with GLIM. ${ }^{46}$

Variables for the exposure terms were coded 0 for low exposure and 1 for high exposure. Indicator terms for age and sex were coded 0 for references ( $\leqslant 40$ years and women respectively) and 1 ( $>40$ years and men respectively).

Two binary indicator variables were used for the cumulative exposure variable with 3 strata ( $<6$ years, $6-15$ years and $>15$ years). Separate

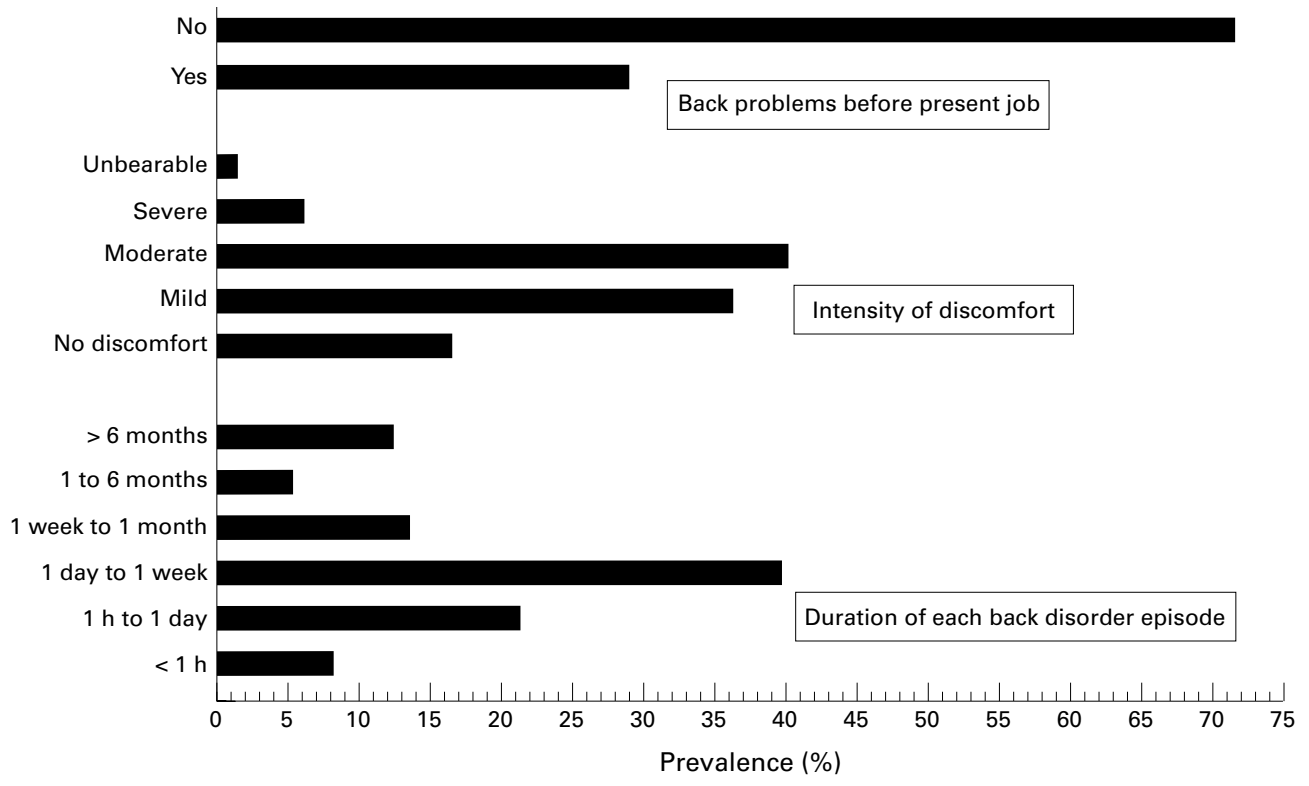

Figure 1 The prevalence (\%) of self reported recurrent back disorders by intensity, duration, and time of onset. 


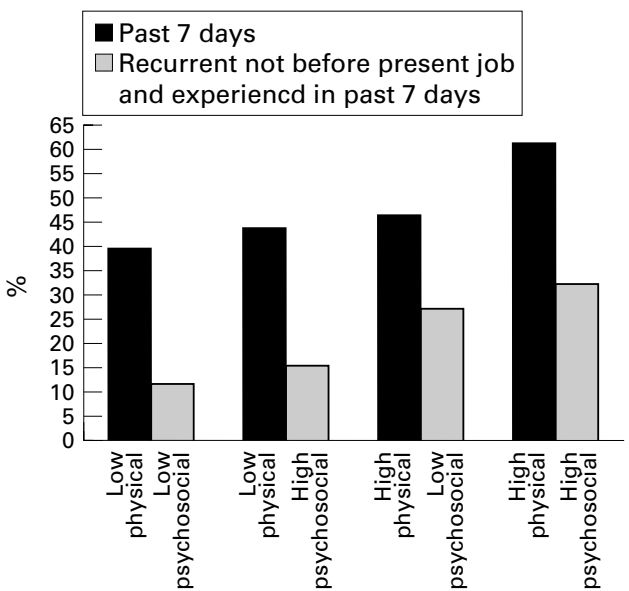

Figure 2 The prevalence per 100 people at risk of self reported back disorders for each exposure group.

modelling was performed for the mixed sex population and men only.

ASSESSMENT OF INTERACTIONS

A departure from an additive interaction risk model was used to assess potential interactions. The aetiological proportion due specifically to the interaction between physical and psychosocial exposures among all cases jointly exposed was calculated with the ORs from the models. ${ }^{17} 47$

\section{Results}

STUDY POPULATION CHARACTERISTICS

Of the 1514 workers invited to participate in the survey, 891 workers returned the questionnaire $(59 \%)$. Twenty two respondents returned uncompleted questionnaires giving a survey response of $57 \%$. A higher response rate was obtained for office workers $(82 \%)$ than manual workers (49\%), drivers ( $72 \%)$, and technicians $(42 \%)$.

Of the 869 responses, 818 had provided the exposure and outcome data for classification. Table 2 shows the distribution of the 818 subjects within each exposure group. In the undefined exposure group 180 workers were classified between low and high physical exposure. These workers did not differ from the workers included in the risk analysis for age, sex, cumulative exposure, or musculoskeletal outcomes.
Of the workers in the undefined exposure group $60 \%$ had high psychosocial exposure. The prevalence of musculoskeletal outcomes did not differ between low and high psychosocial exposure in the undefined physical exposure group.

The low physical-low psychosocial exposure group contained men who were older and had greater cumulative exposure than did the other exposure groups (table 3). Men and women were not evenly distributed throughout the exposure groups. There were no women classified as having high physical exposure. There was also no difference in the distribution of age and years of exposure for women in the low physical-low psychosocial and low physical - high psychosocial exposure groups. It was further noted that women and men performed sedentary office work but only men performed manual work and delivery driving.

\section{BACK DISORDERS}

Of the respondents $39 \%$ had (recurrent) back problems $>3$ times a year or lasting $>1$ week (table 4). Figure 1 shows that about half of these cases had back problems that subsided within 1 day to 4 weeks. About three quarters of the cases with recurrent back problems had mild to moderate discomfort at the time of the study and about $70 \%$ of the reported cases of recurrent back problems were not present before starting the present job. The 7 day prevalence of low back pain (49\%) was lower than the 12 month prevalence $(61 \%)$. Recurrent back problems not present before the present job and that were also present within the past 7 days were experienced by $23 \%$ of respondents.

Figure 2 shows the percentage prevalence of the musculoskeletal outcomes used to assess the risks for each exposure group. The prevalence of symptoms was higher in the high physical-high psychosocial exposure group than in the other exposure groups. The prevalence in high physical-low psychosocial exposure for both outcomes was slightly greater than that for the low physical-high psychosocial exposure group.

Table 5 Site combined age and cumulative exposure for each sex across exposure groups

\begin{tabular}{|c|c|c|c|c|}
\hline & \multicolumn{4}{|l|}{ Exposure } \\
\hline & $\begin{array}{l}\text { Low physical, } \\
\text { low psychosocial }\end{array}$ & $\begin{array}{l}\text { Low physical, high } \\
\text { psychosocial }\end{array}$ & $\begin{array}{l}\text { High physical, low } \\
\text { psychosocial }\end{array}$ & $\begin{array}{l}\text { High physical, high } \\
\text { psychosocial }\end{array}$ \\
\hline \multicolumn{5}{|c|}{ Male and female population: } \\
\hline \multicolumn{5}{|c|}{ Low back pain in the past 7 days: } \\
\hline Crude OR $(95 \% \mathrm{CI})$ & 1.00 & $1.2(0.72$ to 2.01$)$ & $1.33(0.84$ to 2.12$)$ & $2.41(1.51 \text { to } 3.85)^{\star \star \star \star}$ \\
\hline Crude PRR (95\% CI) & 1.00 & $1.11(0.84$ to 1.48$)$ & $1.18(0.91$ to 1.52$)$ & $1.55(1.23 \text { to } 1.95)^{\star \star \star \star}$ \\
\hline \multicolumn{5}{|c|}{ Recurrent back problems not experienced before the present job and also experienced in the past 7 days: } \\
\hline Crude OR $(95 \%$ CI $)$ & 1.00 & $1.4(0.65$ to 2.99$)$ & $2.80(1.48 \text { to } 5.35)^{\star \star \star}$ & $3.58(1.99 \text { to } 6.77)^{\star \star \star \star}$ \\
\hline Crude PRR (95\% CI) & 1.00 & $1.34(0.73$ to 2.46$)$ & $2.32(1.39 \text { to } 3.84)^{\star \star \star}$ & $2.76(1.68 \text { to } 4.52)^{\star \star \star \star}$ \\
\hline \multicolumn{5}{|c|}{ Male population only: } \\
\hline \multicolumn{5}{|c|}{ Low back pain in the past 7 days: } \\
\hline Crude OR $(95 \% \mathrm{CI})$ & 1.00 & $1.53(0.68$ to 3.46$)$ & $1.77(0.95$ to 3.33$)$ & $2.97(1.58 \text { to } 5.62)^{\star \star \star}$ \\
\hline Crude PRR (95\% CI) & 1.00 & $1.30(0.82$ to 2.06$)$ & $1.41(0.97$ to 2.05$)$ & $1.79(1.25 \text { to } 2.57)^{\star \star \star}$ \\
\hline \multicolumn{5}{|c|}{ Recurrent back problems not experienced before the present job and also experienced in the past 7 days: } \\
\hline Crude OR $(95 \% \mathrm{CI})$ & 1.00 & $1.00(0.32$ to 3.03$)$ & $2.08(0.94$ to 4.72$)$ & $2.48(1.12 \text { to } 5.62)^{\star}$ \\
\hline Crude PRR (95\% CI) & 1.00 & $1.00(0.42$ to 2.35$)$ & $1.79(0.96$ to 3.32$)$ & $2.03(1.10 \text { to } 3.74)^{\star}$ \\
\hline
\end{tabular}

${ }^{\star} \mathrm{p}<0.05 ;{ }^{\star \star} \mathrm{p}<0.01 ;{ }^{\star \star \star} \mathrm{p}<0.001 ;{ }^{\star \star \star \star} \mathrm{p}<0.0001$. 
Table 6 Mixed sex models for symptoms of low back pain experienced in the past 7 days

\begin{tabular}{|c|c|c|c|c|}
\hline Variable & $O R$ & $(95 \% C I)$ & $P P R$ & $(95 \% C I)$ \\
\hline \multicolumn{5}{|l|}{ Sex: } \\
\hline Women & 1 & & 1 & \\
\hline Men & 0.80 & 0.47 to 1.35 & 1.02 & 0.77 to 1.35 \\
\hline \multicolumn{5}{|l|}{ Age: } \\
\hline$\leqslant 40$ & 1 & & 1 & \\
\hline$>40$ & 0.78 & 0.53 to 1.15 & 0.88 & 0.73 to 1.07 \\
\hline \multicolumn{5}{|l|}{ Duration of the job (y): } \\
\hline$<6$ & 1 & & 1 & \\
\hline $6-15$ & 1.10 & 0.69 to 1.75 & 1.00 & 0.81 to 1.25 \\
\hline$>15$ & 0.89 & 0.54 to 1.46 & 0.94 & 0.72 to 1.23 \\
\hline Low physical, low psychosocial & 1 & & 1 & \\
\hline Low physical, high psychosocial & 1.04 & 0.62 to 1.76 & 1.04 & 0.77 to 1.41 \\
\hline High physical, low psychosocial & 1.39 & 0.81 to 2.40 & 1.10 & 0.81 to 1.49 \\
\hline High physical, high psychosocial & 2.35 & 1.36 to 4.05 & 1.40 & 1.05 to 1.86 \\
\hline
\end{tabular}

Table 7 Mixed sex models for recurrent back problems not before present job and in the past 7 days

\begin{tabular}{|c|c|c|c|c|}
\hline Variable & $O R$ & $(95 \% C I)$ & $P P R$ & $(95 \% C I)$ \\
\hline \multicolumn{5}{|l|}{ Sex: } \\
\hline Women & 1 & & 1 & \\
\hline Men & 1.48 & 0.67 to 3.27 & 1.71 & 0.92 to 3.19 \\
\hline \multicolumn{5}{|l|}{ Age: } \\
\hline$\leqslant 40$ & 1 & & 1 & \\
\hline$>40$ & 0.61 & 0.37 to 0.99 & 0.68 & 0.49 to 0.95 \\
\hline \multicolumn{5}{|l|}{ Duration of the job (y): } \\
\hline$<6$ & 1 & & 1 & \\
\hline $6-15$ & 2.86 & 1.69 to 4.84 & 2.06 & 1.46 to 2.90 \\
\hline$>15$ & 3.67 & 2.00 to 6.70 & 2.62 & 1.76 to 3.89 \\
\hline Low physical, low psychosocial & 1 & & 1 & \\
\hline Low physical, high psychosocial & 1.35 & 0.61 to 2.97 & 1.24 & 0.66 to 2.45 \\
\hline High physical, low psychosocial & 2.38 & 1.13 to 4.99 & 1.81 & 1.02 to 3.21 \\
\hline High physical, high psychosocial & 2.99 & 1.43 to 6.24 & 2.07 & 1.18 to 3.64 \\
\hline
\end{tabular}

Table 8 Men only models for symptoms of low back pain experienced in the past 7 days

\begin{tabular}{|c|c|c|c|c|}
\hline Variable & $O R$ & $(95 \% C I)$ & $P P R$ & $(95 \% C I)$ \\
\hline \multicolumn{5}{|l|}{ Age: } \\
\hline$\leqslant 40$ & 1 & & 1 & \\
\hline$>40$ & 0.83 & 0.53 to 1.30 & 0.90 & 0.73 to 1.12 \\
\hline \multicolumn{5}{|l|}{ Duration of the job $(y)$ : } \\
\hline$<6$ & 1 & & 1 & \\
\hline $6-15$ & 1.20 & 0.73 to 1.96 & 1.11 & 0.89 to 1.38 \\
\hline$>15$ & 1.11 & 0.61 to 2.00 & 1.07 & 0.80 to 1.44 \\
\hline Low physical, low psychosocial & 1 & & 1 & \\
\hline Low physical, high psychosocial & 1.47 & 0.68 to 3.15 & 1.28 & 0.80 to 2.04 \\
\hline High physical, low psychosocial & 1.67 & 0.90 to 3.10 & 1.37 & 0.93 to 2.02 \\
\hline High physical, high psychosocial & 2.80 & 1.51 to 5.19 & 1.74 & 1.19 to 2.52 \\
\hline
\end{tabular}

Table 9 Men only model for recurrent back problems not before present job and in the past 7 days

\begin{tabular}{lllll}
\hline Variable & OR & (95\% CI) & PPR & (95\% CI) \\
\hline $\begin{array}{l}\text { Age: } \\
\quad \leq 40\end{array}$ & 1 & & 1 & \\
$\quad>40$ & 0.52 & 0.30 to 0.91 & 0.64 & 0.45 to 0.91 \\
$\quad \begin{array}{l}\text { Duration of the job (y): } \\
\quad 6\end{array}$ & 1 & & 1 & \\
$\quad 6-15$ & 2.84 & 1.64 to 4.93 & 2.03 & 1.42 to 2.88 \\
$\quad>15$ & 1.13 & 2.08 to 8.20 & 2.74 & 1.81 to 4.14 \\
Low physical, low psychosocial & 1.16 & 0.40 to 3.33 & 1.10 & 0.46 to 2.62 \\
Low physical, high psychosocial & 1.17 & 0.96 to 4.89 & 1.83 & 0.96 to 3.48 \\
High physical, low psychosocial & 2.17 & 1.24 to 6.17 & 2.11 & 1.12 to 3.97 \\
High physical, high psychosocial & 2.76 & & & \\
\hline
\end{tabular}

CRUDE ANALYSIS

Mixed sex population

For the mixed sex population, the crude risk measures for both musculoskeletal outcomes (table 5) indicated an increased risk for each exposure group compared with low physicallow psychosocial exposure, although the increased risk was greatest for the high physicalhigh psychosocial exposure group. The ORs for high physical-high psychosocial exposure was significant for the 7 day prevalence of low back pain (OR 2.41 95\% confidence interval (95\% CI) 1.51 to 3.85 ) and also for recurrent back disorders not present before the current job and also present within the past 7 days (OR $3.5895 \%$ CI 1.99 to 6.77 ).

\section{Male population only}

A separate analysis of the data for men only (table 5) showed a similar trend as for the mixed sex population analysis. The crude risk measures for both musculoskeletal outcomes indicated a higher risk for the high physical exposure groups than the low physical-low psychosocial exposure group. The risk was greatest for the high physical-high psychosocial exposure group and was significant $(\mathrm{p}<0.001)$ for the 7 day prevalence of low back pain (OR 2.97 95\%CI 1.58 to 5.62); and recurrent back disorders not present before the current job and present within the past 7 days (OR 2.48 95\% CI 1.12 to 5.62).

MODELLING

Mixed sex population

The exposure variables in the logistic regression analysis (table 6) for the 7 day prevalence of back pain were similar to the crude ORs. Sex, age, and years in the job were not found to be important effect modifiers for this outcome. The only variable producing a 95\% CI >1 was high physical-high psychosocial exposure (OR 2.35 95\%CI 1.36 to 4.05).

For recurrent back problems not present before the present job and experienced within the past 7 days (table 7 ), being exposed to high physical exposure resulted in increased risks that were confident at the $95 \%$ level. The risk was greatest, however, for those workers exposed to high physical and high psychosocial exposure. The risk also increased with the increasing number of years spent in this employment (ORs 2.86-3.67). Being >40 years old reduced the risks of recurrent back problems with the $95 \% \mathrm{CI}<1$.

\section{Male population only}

For low back pain experienced in the past 7 days (table 8), high physical-high psychosocial exposure was the only variable that had $95 \%$ CIs $>1$. An OR of 2.8 (95\% CI 1.51 to 5.19) was present for this exposure group. The risk was highest for the high physical exposure groups as in the crude ORs.

For recurrent back problems (table 9), high physical-high psychosocial exposure produced the highest risk measures of the exposure groups and the $95 \%$ CIs were $>1$. The risk increased with the increasing number of years spent exposed, with those exposed 6-15 years having an OR of 2.84 (95\% CI 1.64 to 4.93 ) and those with $>15$ years OR of 4.13 (95\%CI 2.08 to 8.20 ). As for the mixed sex population, being $>40$ years of age reduced the risks of recurrent back problems OR 0.52 (95\% CI 0.3 to 0.91 ).

INTERACTIONS

The proportion of disease (adjusted ORs) among those with high exposures to both physical and psychosocial factors that was attributable to their interaction (fig 3) was greater for low back disorders experienced in 


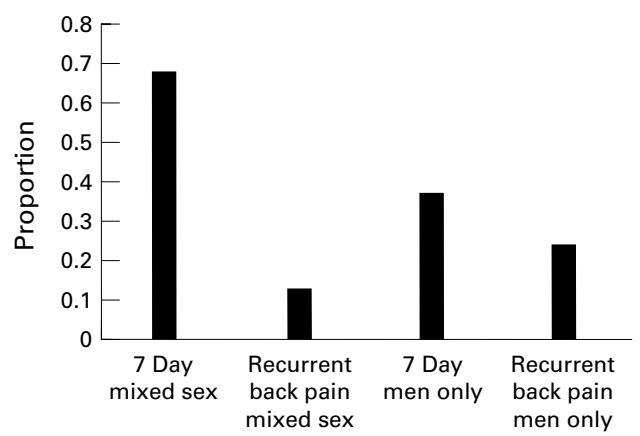

Figure 3 The proportion of back disorders due to interaction between physical and psychosocial risk factors at work.

the past 7 days than for the recurrent back disorder. Of low back disorders experienced during the past 7 days in the mixed sex population $68 \%$ were due to interaction effects. This proportion increased to $75 \%$ with prevalence proportion ratios. The interaction effects for the men only population was relatively low $(37 \%)$. For recurrent back disorders, the interaction effect was greater for the analysis of men only than the mixed sex population.

\section{Discussion}

RISK FACTORS FOR SELF REPORTED BACK DISORDERS

The greatest risk associated with self reported back disorders was from high exposure to both physical and psychosocial work factors. Physical or psychosocial work factors acting in the relative absence of the other also increased the risk of these disorders. The combination of high physical exposure and low psychosocial exposure increased the risk of recurrent back disorders in the mixed sex population (adjusted OR $2.38,95 \%$ CI 1.13 to 4.99 ) indicating that physical risk factors at work acting relatively independently may increase risks. Tentative associations for exposure to low physical — high psychosocial exposure and musculoskeletal disorders were found.

Men who had been exposed for $\geqslant 6$ years in highly physical jobs involving manual work and driving had an increased risk of recurrent back problems (ORs 2.84-4.13). Cumulative exposure has been shown to increase the risk of work related musculoskeletal disorders in other studies. A cross sectional study showed that 10 years of professional driving incurred a risk of self reported neck and back pain (OR 3.43, $95 \%$ CI 1.5 to 7.81 ) and the risk increased non-linearly with an increase in $>10$ years of driving. ${ }^{48}$ As in this study, other studies ${ }^{48}$ have found that age seemed to be unrelated to back and neck pain. Baseline data from a longitudinal study also showed that male bricklayers (lifting and carrying bricks weighing 5-24 kg at a rate of 100 times an hour) had twice the risk of clinically diagnosed low back disorders ${ }^{49}$ after controlling for age, previous work related accidents, and individual factors.

In the study reported here, recurrent back disorders had greater crude ORs than the 7 day prevalence of low back disorders. This result has been found in other studies-for example, a prospective study of female nurses performing manual work showed that the risk of self reported low back pain (lasting $>1$ day) increased with the total duration of previous pain and was greater for symptoms that had been present within the preceding year than those present $>1$ year before entry into the study. ${ }^{50}$

Cumulative exposure, age, and sex were not important confounders for symptoms such as aches, pain, and discomfort in the lower back experienced in the past 7 days. It may be that the experience of fleeting aches and pains may not be associated with these factors or that the 7 day prevalence may reflect different aetiologies. These may mask the true effect of these factors. It has been shown that with a non-specific definition of low back pain (pain, tenderness, stiffness, or other trouble in the lowest part of the back in the preceding year), only one significant association was found for heavy physical work compared with sedentary work. However, the associations with other factors became significant and stronger associations were found with heavy physical work when an analysis was performed on a subgroup with low back pain for $>30$ days. Associations for physical work and other factors became weaker for a subgroup with low back pain for $<30$ days. $^{51}$

\section{INTERACTIONS}

The data from the logistic regression analyses for the mixed and the men only populations suggested that interactions between physical and psychosocial risk factors at work were present as indicated by a departure from an additive model of risk. Workers exposed jointly to both sets of physical and psychosocial risk factors at work experienced the biological effects of high physical exposure, high psychosocial exposure, and the interaction effects of these two factors. The proportion of the interaction effect varied according to the outcome and the mixed and men only groups. The derivation of a potential interactive effect in multiple logistic regression by estimating the coefficient of a product term in the model is incorrect. ${ }^{17}$ It could easily be inferred that there is no evidence of an interaction with such an approach when there might be considerable evidence of a deviation from additivity. ${ }^{52}$ Logistic regression models can be used to assess interactions with the method outlined in this paper.

To our knowledge no other study has investigated the potential interaction effects between physical and psychosocial risk factors at work on the risks of work related back disorders. A previous cross sectional survey investigated the combined effects of physical and psychosocial exposure. The combined effects of a heavy lifting and a poor psychosocial exposure compared with exposure to neither factor have been shown to increase the risk of back problems requiring medical attention within the previous year (OR 2.68, 95\% CI 2.02 to 3.57 ) in a Swedish study of about 22000 workers. 
The OR for the combined factors was greater than the ORs for lifting and a poor psychosocial work environment when considered separately. Possible interaction effects were not investigated because workers were not classified into low physical-high psychosocial or high physical-low psychosocial exposure groups. The relations found by others for the lower back ${ }^{14}$ concur with the combined effect of high physical and high psychosocial exposure found in this study.

PLAUSIBILITY OF THE INTERACTIONS

Illustrative models of the pathways by which physical and psychosocial factors may influence work related musculoskeletal disorders have been proposed..$^{735}$ It is thought that psychosocial work factors may influence physical exposure-for example, lifting frequency and poor working postures may be increased by perceived pressure on time and high work demands. High social support between workers and managers may promote the development of ergonomic strategies to reduce physical exposure-such as alterations in work technique, lifting equipment, taking rests, and being involved in organisational health and safety issues. ${ }^{55}$

Current explanations of how psychosocial work factors may also directly influence work related musculoskeletal disorders are through two mediating routes-neuromuscular tension and local sensitivity to pain. Neuromuscular tension has been correlated with psychosocial risk factors at work and the development of work related musculoskeletal disorders, defined as muscle pain, but the relations are unclear. ${ }^{56}$ Three mechanisms have been proposed for this possible correlation. Firstly, psychosocial factors act through increased neuromuscular tension. Secondly, psychosocial factors may act through an interaction with neuromuscular tension brought about by physical work demands. Thirdly, psychosocial factors may act through an alternative mechanism independent of neuromuscular activity. At present, the most convincing evidence suggests that neuromuscular activity and psychosocial factors can act independently towards the development of work related musculoskeletal disorders. ${ }^{56-58}$ Also, a feeling of general tension (a psychological stress symptom) may also act independently of muscle fibre activation measured by surface electromyography. ${ }^{59}$

Alternatively the strain from psychosocial exposure may indirectly modify the biological effect of the biomechanical load upon the development of work related musculoskeletal disorders. For example, people experiencing high exposure to physical and psychosocial risk factors at work may have increased sensitisation to discomfort and distress that may affect individual capacity such that the response to further strain or physical and psychosocial exposure is intensified. An alternative model proposed that the experience of back disorders and other work related musculoskeletal disorders may also alter perceptions of psychosocial work factors. This may increase the psychoso- cial strain that may then increase the physical work demands on a person with already reduced physical and psychological capacities. ${ }^{2}$ Current models imply that psychosocial work factors are static, however, it has been shown in a longitudinal study of office workers that they are dynamic and the relation between psychosocial work factors and hand-arm discomfort and worker strain can vary over time. ${ }^{60}$

\section{STUDY DESIGN AND BIASES}

Response rates

Although it seems that the participation rate varied between sedentary, manual, and driving jobs, the percentage responses are, nevertheless, large enough to allow valid comparisons. Also, sufficient numbers were classified into each exposure group to provide the required study power at the $95 \%$ CI for the mixed sex population.

\section{Exposure criteria}

Predetermined exposure criteria were used for classification of individual cases into low or high physical and psychosocial exposure groups. Combinations of long term whole body vibration and frequent lifting have produced the highest risks of low back pain, neck pain, and shoulder pain compared with the risks associated with individual factors. ${ }^{61}$ Combinations of high psychological demands, low decision latitude, and low social support may also result in the greatest risks compared with individual factors. ${ }^{41} 42$

For physical exposures in this study, 180 subjects did not satisfy the criteria for classification into low or high physical exposures. The contrast between low and high physical exposure was required to reduce the potential effects of exposure misclassification. ${ }^{62}$ The removal of these subjects from the risk analyses did not affect the distribution of age, sex, years of exposure, and musculoskeletal outcomes. The disadvantage of such an approach is that a large variation in exposure is required within the study population to provide sufficient numbers with contrast between low and high exposures. Also a large study population is needed to provide sufficient study power, especially for studying interactions. ${ }^{63}$

\section{OCCUPATION GROUPS WITHIN EACH EXPOSURE} GROUP

This study investigated work tasks that could be classified as general manual, delivery driving, or sedentary office work. As expected, individual workers from each job classification were spread across exposure groups. Most workers performing delivery driving and general manual work were classified into the high physical exposure groups. Most sedentary office workers were classified into the two low physical exposure groups. The risk associated with the high physical exposure groups was supported by data from a United States national survey. ${ }^{64}$ The occupational groups at the highest risk of back pain all included heavy physical work and driving motor vehicles. Occupational groups that performed sedentary 
work were not considered to be at a high risk of back pain.

POTENTIAL UNDERESTIMATION OF RISKS OF BACK DISORDERS

Sedentary office workers in this study population mostly performed computer work and answered continuous customer phone enquiries for most or all of the working day. Therefore, postures were constrained to sitting for most of the working day. The prevalence of back disorders in the past 7 days was $40 \%$ and $44 \%$ for low physical-low psychosocial exposure and low physical-high psychosocial exposure, respectively. High prevalences of back pain in light (static) work have been shown in some professions. ${ }^{65}$ The estimates of risk associated with low back disorders may have been underestimated as a result of the unexposed reference group potentially being at risk of low back disorders relative to a sedentary worker group not exposed to constrained sedentary sitting postures. A J shaped relation between sedentary, mixed, and heavy occupations has been supported for the incidence of back pain and the development of pathological spinal defects. ${ }^{66}$ More research is needed on the measured exposure-effect relation between prolonged sitting and back disorders. ${ }^{628} 29$

VALIDITY OF EXPOSURE ASSESSMENT

Reducing misclassification of exposure was dependent on the accuracy of the self reported exposure data. The self reported questions had been previously validated ${ }^{20}{ }^{21}$ and also small scale validation tests $(n=12)$ were performed in the study population. ${ }^{2}$ For the physical exposure criteria, the results concurred with other studies showing that there was good agreement between self reported exposures for lifting (Spearman $r 0.95$ and 0.93 for lifting $6-15 \mathrm{~kg}$ and lifting $16-45 \mathrm{~kg}$, respectively) and the duration of sitting (Spearman $r$ 0.91) and poor agreement for duration spent in different postures bending forward (Spearman $r$ 0.00). ${ }^{20}{ }^{67-69}$ The lack of correlation between self reports and electrogoniometer measurements (Biometrics, Gwent, UK) for trunk postures justified its exclusion as an exposure criterion despite its relative importance as a risk factor during the performance of static work tasks and tasks requiring the exertion of force. ${ }^{70}$ The physical exposure questionnaire was able to classify people into low and high exposure groups. No subjects were misclassified from high physical exposure to low physical exposure or vice versa, thus exposure misclassification was minimised. In general, there was fair to excellent correlation between self reported psychosocial exposure and that measured by structured interview. The psychosocial self reported questionnaire was able to sufficiently classify people into low and high psychosocial exposure groups despite the misclassification of a proportion of subjects into a high psychosocial exposure group when the interview classified those subjects into a low exposure group (sensitivity was 1.00 and the specificity was $0.56)$.
The cross sectional study design allowed the relation between exposure and disease to be examined for individual people at the same time. Therefore, it was difficult to determine whether the exposure preceded the outcome with such a study design. ${ }^{46} 71$ The associations between recurrent back disorders and risks were found for symptoms not experienced before the present job, which provided some indication that exposure preceded the outcome assuming that recall bias was minimised. Collecting retrospective data may lead to either differential or non-differential exposure misclassification bias. It was not possible to assess whether there was evidence of differential or non-differential exposure misclassification but previous studies have suggested that subjects with back complaints that have either been expressed as pain within the past 12 months ${ }^{20}$ and pain on $>30$ days during the preceding year ${ }^{67}$ may overestimate exposure. However, the evidence is not conclusive. In this study, subjects were asked to report exposures for the current day to attempt to minimise any misclassification bias. A study showed that a short recall period (symptoms in the past 7 days or right now) would probably reflect effects of current exposures at work. ${ }^{72}$ In the presence of differential exposure misclassification the bias effect may be minimised with the 7 day prevalence rather than the 12 month prevalence, as subjects are less prone to make recall errors and positive symptoms may have less of an adverse effect upon recall.

\section{HEALTHY WORKER EFFECTS}

Analysis of medical severance data for work related musculoskeletal disorders showed that there was a healthy worker selection bias in the total study population. The data could not be disclosed for reasons of confidentiality. However, adjustment of the crude ORs for medical severance from back injury were not greatly different from the crude ORs suggesting that the size of the selection bias due to workers lost from medical severance was not great. An interaction remained between high exposures to physical and psychosocial risk factors at work. Adjustment could not be made for workers who had resigned or had not received medical severance. The survivor population tended to be younger and have less cumulative work exposure, which might make them a healthier population. This may partially explain why age was found to be a protective factor for recurrent back problems contrary to other epidemiological studies. ${ }^{14657374}$ This effect was in accordance with another study that showed a selection bias. ${ }^{75}$ The selection bias, can therefore, not only mask associations but can also result in apparent improvement of low back trouble with age and the number of years spent exposed at work. For recurrent back disorders in this study, there was an improvement with age but not for increasing years employed. This suggests that cumulative exposure is a risk factor for workers who are relatively young.

The average measures for the number of years spent exposed and age were higher in the 
low physical-low psychosocial exposure reference group. This may have increased the prevalence of work related musculoskeletal disorders in the exposure reference group, which would have reduced the relative effect of the risk for the other exposure groups. When years exposed was entered into the models there was little change in the estimates for the exposure variables suggesting that a healthy worker effect may not be due to the years spent exposed but older workers leaving the company instead. Workers could not move from heavy physical jobs to lighter physical jobs or vice versa in this study population so the risk estimates could not have been underestimated for this reason.

The age and sex distribution of the total study population had a similar distribution to the survey response population. Therefore, a response bias due to age and sex differences between the response and non-response population was unlikely. Response bias due to outcome or years spent exposed could not be assessed.

\section{Conclusions}

Physical and psychosocial risk factors at work may act independently to increase risks or they may also interact to further increase the risks of self reported back disorders. Strategies aimed at the prevention or intervention of risks for work related back disorders should reduce exposure both to physical and psychosocial risk factors at work. Further epidemiological studies concerned with work related back disorders and other work related musculoskeletal disorders are needed to confirm the presence of interactions between physical and psychosocial risk factors at work.

Appendix: Questions used to formulate Boolean algebra expressions from which the physical exposure criteria were decided.

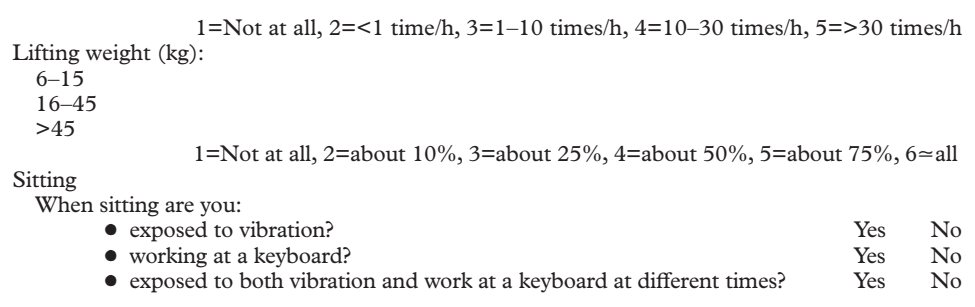

1 Burdorf A, Sorock GS. Positive and negative evidence of risk factors for back disorders. Scand 7 Work Environ Health 1997;23:243-56

2 Devereux JJ. A study of interactions between work risk factors and work related musculoskeletal disorders [dissertation]. and work related musculoskeletal disorder.

3 Ferguson SA, Marras W. A literature review of low back disorder surveillance measures and risk factors. Clinical Biomechanics 1997;12:211-26.

4 Putz-Anderson V, Bernard BP, Burt SE, et al. Musculoskeletal disorders and workplace factors: a critical review of epidemiologic evidence for work-related musculoskeletal disorders of the neck, upper extremity, and low back. Cincinnati: Department of Health and Human Services (National Institute for Occupational Safety and Health), 1997. (Publication No 97-141.)

5 Garg A, Moore JS. Epidemiology of low back pain in industry. State of the Art Reviews in Occupational Medicine 1992;7: 593-609.

6 Riihimäki H. Low-back pain, its origin and risk indicators. Scand 7 Work Environ Health 1991;17:81-90.

7 Bongers PM, de Winter CR, Kompier MAJ, et al. Psychosocial factors at work and musculoskeletal disease. Scand $\mathcal{f}$ Work Environ Health 1993;19:297-312.

8 Burton AK, Tillotson KM, Symonds TL, et al. Occupational risk factors for the first-onset and subsequent course of low back trouble: a study of serving police officers. Spine 996;21:2612-20.

9 Heliövaara M, Mäkela M, Knekt $\mathrm{P}$, et al. Determinants of sciatica and low-back pain. Spine 1991;16:608-14.

10 Holmstrom EB, Lindell J, Moritz U. Low back and neck/shoulder pain in construction workers: occupational workload and psychosocial risk factors. Part 1. Relationship to low back pain. Spine 1992;17:663-1.

11 Houtman ILD, Bongers PM, Smulders PGW, et al. Psychosocial stressors at work and musculoskeletal problems. Scand 7 Work Environ Health 1994;20:139-45.

12 Johansson JÅ, Rubenowitz S. Risk indicators in the psychosocial and physical work environment for work-related neck, shoulder and low back symptoms: a study among blue and white-collar workers in eight companies. Scand $f$ Rehabil Med 1994;26:131-42.

13 Krause N, Ragland DR, Greiner BA, et al. Psychosocial job factors associated with back and neck pain in public transit operators. Scand f Work Environ Health 1997;23:179-86.

14 Linton SJ. Risk factors for neck and back pain in a working population in Sweden. Work and Stress 1990;4:41-9.

15 Riihimäki H, Viikari-Juntura E, Moneta G, et al. Incidence of sciatic pain among men in machine operating, dynamic physical work, and sedentary work: a three year follow-up. Spine 1994;19:138-42.

16 Kleinbaum DG, Kupper LL, Morgenstern H. Epidemiologic research: principles and quantitative methods. New York: Van Nostrand Reinhold, 1982.

17 Rothman KJ. Modern epidemiology. Boston: Little Brown, 1986.

18 Koopman JS. Interaction between discrete causes. Am $\mathcal{F}$ Epidemiol 1981;113:716-24.

19 Andersson GBJ, Fine LJ, Silverstein BA. Musculoskeletal disorders. In: Levy BS, Wegman DH, eds. Occupational health: recognizing and preventing work-related disease. health: recognizing and preventing

20 Wiktorin C, Karlqvist L, Winkel J. Validity of self-reported exposures to work postures and manual materials handling. exposures to work postures and manual materials

21 Hurrell JJJ, McLaney M. Exposure to job stress-a new psychometric instrument. Scand $f$ Work Environ Health 1988;14(suppl 1):27-8

22 Stewart PA, Herrick RF, Blair A, et al. Highlights of the 1990 Leesburg, Virginia, international workshop on retrospective exposure assessment for occupational epidemiol-
ogy studies. Scand $\mathcal{F}$ Work Environ Health 1991;17:281-5.

23 Armstrong TJ, Buckle P, Fine LJ, et al. A conceptual model for work-related neck and upper-limb musculoskeletal disorders. Scand f Work Environ Health 1993;19:73-84.

24 Nuwayhid IA, Stewart W, Johnson JV. Work activities and the onset of first-time low back pain among New York City the onset of first-time low back pain among New

25 Walsh K, Varnes N, Osmond C, et al. Occupational causes of low-back pain. Scand $\mathcal{F}$ Work Environ Health 1989;15:54-

26 Kelsey JL, Githens PB, White III AA, et al. An epidemiologic study of lifting and twisting on the job and risk for acute prolapsed lumbar intervertebral disc. F Orthop Res 1984;2:61-6.

27 Punnett L, Fine LJ, Keyserling WM, et al. Back disorders and nonneutral trunk postures of automobile assembly workers. Scand $\mathcal{F}$ Work Environ Health 1991;17:337-46.

28 Riihimäki H. Back and limb disorders. In: McDonald JC, ed. Epidemiology of work related diseases. London: BMJ Publishing Group, 1995:207-38.

29 Wickström B-O, Kjellberg A, Landström U. Health effects of long-term occupational exposure to whole-body vibration: a review. International fournal of Industrial Ergonomics 1994;14:273-92.

30 Wilder DG. The biomechanics of vibration and low back pain. Am f Ind Med 1993;23:577-88.

31 Johanning E. Back disorders and health problems among subway train operators exposed to whole body vibration. Scand $\mathcal{F}$ Work Environ Health 1991;17:414-19.

32 Bovenzi M, Zadini A. Self-reported low back symptoms in urban bus drivers exposed to whole-body vibration. Spine 1992;17:1048-59.

33 Kelsey JL. An epidemiological study of the relationship between occupations and acute herniated lumbar intervertebral discs. Int f Epidemiol 1975;4:197-205.

34 Kelsey JL, Hardy J. Driving of motor vehicles as a risk factor for acute herniated lumbar intervertebral disc. Am $\mathcal{F}$ Epidemiol 1975;102:63-73.

35 Pietri F, Leclerc A, Boitel L, et al. Low-back pain in commercial travellers. Scand $\mathcal{f}$ Work Environ Health 1992;18:52-8.

36 Hales T, Sauter SL, Peterson MR, et al. Musculoskeletal disorders among visual display terminal users in a telecommunications company. Ergonomics 1994;37:1603-21.

37 Johansson JÅ, Rubenowitz S, Hansevi P, et al. Psychosocial and physical factors at work and their relation to musculoskeletal symptoms among elderly care and child care workers. Book of abstracts of the Proceedings of the Prevention of Musculoskeletal Disorders Conference (PREMUS 95). Montreal, Canada: IRSST 1995;166.

38 Linton SJ, Kamwendo K. Risk factors in the psychosocial work environment for neck and shoulder pain in secretaries. F Occup Med 1989;31:609-13.

39 Toomingas A, Theorell T, Michelsen H, et al. Associations between perceived psychosocial job factors and prevalence of musculoskeletal disorders in the neck and shoulder regions. Book of abstracts of the Proceedings of the Prevention of Musculoskeletal Disorders Conference PREMUS 92. Solna, Sweden: National Institute of Occupational Health, 1992;289-90. 
40 Karasek RA, Theorell T. Healthy work: stress, productivity, and the reconstruction of working life. New York: Basic Books, 1990.

41 Holmstrom EB, Lindell V, Moritz U. Healthy lower backs in the construction industry in Sweden. Work and Stress 1993; $7: 259-71$.

42 Johansson JÅ. Psychosocial factors at work and their relation to musculoskeletal symptoms [dissertation]. Göteborg: University of Göteborg, 1994.

43 Oppenheim AN. Questionnaire design and attitude measurement. London: Heinemann, 1966.

44 Hildebrandt VH. Validity of self-reported musculoskeletal complaints. Book of abstracts of the Proceedings of the Prevention of Musculoskeletal Disorders Conference (PREMUS 92). Solna, Sweden, National Institute of Occupational Health, 1992;17:125-7.

45 Hughes RE, Silverstein BA, Evanoff BA. Risk factors for work-related musculoskeletal disorders in an aluminium work-related musculoskeletal disorders

46 Checkoway H, Pearce NE, Crawford-Brown DJ. Research methods in occupational epidemiology. Oxford: Oxford methods in occupational

47 Walker AM. Proportion of disease attributable to the combined effect of two factors. Int $\mathcal{F}$ Epidemiol 1981;10:81 5.

48 Krause N, Ragland DR, Greiner BA, et al. Physical workload and ergonomic factors associated with prevalence of back and neck pain in urban transit operators. Spine 1997;22: 2117-27.

49 Stürmer T, Luessenhoop S, Neth A, et al. Construction work and low back disorder: preliminary findings of the Hamburg construction worker study. Spine 1997;22:255863.

50 Smedley J, Egger P, Cooper C, et al. Prospective cohort study of predictors of incident low back pain in nurses. BMF 1997;314:1225-8.

51 Leboeuf-Yde C, Lauritsen JM, Lauritzen T. Why has the search for causes of low back pain largely been nonconclusearch for causes of low back pain largely been nonconclu-
sive? Spine 1997;22:877-81.

sive? Spine 1997,22:877-81

2 Greenland S. Limitations of the logistic analysis of epidemiologic data. Am F Epidemiol 1979;110:693-8.

53 Sauter SL, Swanson NG. An ecological model of musculoskeletal disorders in office work. In: Moon SD, Sauter SL, eds. Beyond biomechanics: psychosocial aspects of musculoskeletal disorders in office work. London: Taylor and Francis, 1996:1-22

54 National Research Council. Work-related musculoskeletal disorders: a review of the evidence. Washington: National Research Council, 1998.

55 Torp S, Riise T, Moen BE. Psychosocial work environment and "ergonomic coping" among car mechanics. In: Experience to innovation: Proceedings of the 13th Triennial Congress of the IEA. Tampere, Finland: Finnish Institute of Occupational Health, 1997:114-16.

56 Westgaard RH. Effects of psychological demand and stress on neuromuscular function. In: Moon SD, Sauter SL, eds. Beyond biomechanics: psychosocial aspects of musculoskeletal disorders in office work. London: Taylor and Francis, disorders in

57 Vasseljen Jr O, Westgaard RH. Can stress-related shoulder and neck pain develop independently of muscle activity? Pain $1996 ; 64: 221-30$.

58 Theorell T. Possible mechanisms behind the relationship between the demand-control-support model and disorders of the locomotor system. In: Moon SD, Sauter SL, eds. Beyond biomechanics: psychosocial aspects of musculoskeletal disorders in office work. London: Taylor and Francis, 1996:65-73.

59 Vasseljen Jr O, Westgaard RH, Larsen S. A case-control study of psychological and psychosocial risk factors for shoulder and neck pain at the workplace. Int Arch Occup Environ Health 1995;66:375-82.

60 Carayon P, Yang C-L, Lim S-Y. Examining the relationship between job design and worker strain over time in a sample of office workers. Ergonomics 1995;38:1199-211.

61 Magnusson M, Pope MH, Wilder DG, et al. Are occupational drivers at an increased risk for developing musculoskeletal disorders. Spine 1996;21:710-17.

62 Hernberg S. Introduction to occupational epidemiology. Michigan: Lewis, 1992.

63 Gail MH. A bibliography and comments on the use of statistical models in epidemiology in the 1980s. Stat Med 1991;10:1819-95.

64 Guo L, Tanaka S, Cameron LL, et al. Back pain among workers in the United States: national estimates and workers at high risk. Am F Ind Med 1995;28:591-602.

65 Hildebrandt VH. Back pain in the working population: prevalence rates in Dutch trades and professions. Ergonomics 1995;38:1283-98.

66 Videman T, Nurminen M, Troup JDG. Lumbar spinal pathology in cadaveric material in relation to history of back pain, occupation, and physical loading. Spine 1990;15:728-40.

67 Viikari-Juntura E, Rauas S, Martikainen R, et al. Validity of self-reported physical work load in epidemiologic studies on musculoskeletal disorders. Scand $\mathcal{F}$ Work Environ Health 1996;22:251-9.

68 Wiktorin C, Hjelm E, Winkel J, et al. Reproducibility of a questionnaire for assessment of physical load during work and leisure time. F Occup Environ Med 1996;38:190-201.

69 Andrews DM, Norman RW, Wells RP, et al. The accuracy of self-report and trained observer methods for obtaining estimates of peak load information during industrial work. International fournal of Industrial Ergonomics 1997;19:44555.

70 Haselgrave CM. What do we mean by a "working posture"? Ergonomics 1994;37:781-99.

71 Sorock GS, Courtney TK. Epidemiologic concerns for ergonomists: illustrations from the musculoskeletal disorder literature. Ergonomics 1996;39:562-78.

72 Hagberg M, Toomingas A. Ouestionnaire designs-recall period of symptoms and general versus precise question. Book of abstracts of the Conference on the Active Health Surveillance of
Work-related Musculoskeletal Disorders. Sweden: National Work-related Musculoskeletal Disorders.
Institute of Working Life, 1996;24-5.

73 Leino P, Berg M, Puska P. Is back pain increasing? Results from national surveys in Finland during 1978/9-1992. Scand F Rheumatol 1994;23:269-76.

74 Liira JP, Shannon HS, Chambers LW, et al. Long term back problems and physical work exposures in the 1990 Ontario health survey. Am f Public Health 1996;86:382-7.

75 Heuer $\mathrm{H}$, Klimmer F, Kylian $\mathrm{H}$, et al. Musculoskeletal problems in bricklayers as a function of length of employment: The role of a secondary selection by low-back pain. Work and Stress 1996;10:322-35. 